\title{
Assessment of the effect of platelet rich plasma on the healing of operated sacrococcygeal pilonidal sinus by lay-open technique: a randomized clinical trial
}

\author{
Mohamed M. Gohar ${ }^{1,2^{*}}$, Reda F. Ali ${ }^{1}$, Khaled A. Ismail ${ }^{1}$, Taha A. Ismail ${ }^{1}$ and Nahla A. Nosair ${ }^{3}$
}

\begin{abstract}
Background: Sacrococcygeal pilonidal sinus disease (PSD) is an infection of the skin and subcutaneous tissue at the upper part of the natal cleft of the buttocks. Excision and healing by granulation "lay-open" method is still more preferable than other methods of midline closure or using flaps but the healing time is lengthy. The present study was performed to assess the healing promotion effect of platelet-rich plasma (PRP) on the pilonidal sinus wounds treated by the lay-open method.
\end{abstract}

Methods: One hundred patients suffering from PSD were randomly divided into two groups, they were treated by the lay-open method, at General surgery department, Kafr El-Sheik University hospital, Egypt, during the period from December 2018 to December 2019. Group (A) was adopted the regular dressing postoperatively, while group (B) was treated with PRP injection into the wound at 4 and 12 postoperative days.

Results: Accelerated rate of wound healing was detected in group (B) in day 10, with a significant difference detected in days 15, 20, 25 and 30 postoperative, with a mean time of complete healing $45 \pm 2.6$ days in group B, while it was $57 \pm 2.4$ days in group A with a $p$-value of 0.001 which indicates considerable effect in the treated group.

Conclusions: PRP injection is an effective new technique in accelerating the healing of pilonidal wound after surgery, with a significant decrease in post-operative pain, complications and an early return to work.

Trial registration: retrospectively registered. Trial registration number: 12/35/1016 issued on December 2018 from the Institution Review Board at Kafr El Sheikh University. ClinicalTrials.gov identifier: NCT04430413

Keywords: Pilonidal sinus, PRP, Lay-open excision

\footnotetext{
* Correspondence: dr.mmmg.1990@gmail.com

'General Surgery Department, Kafr El Shiekh University Hospital, Kafr El

Shiekh, Egypt

${ }^{2}$ Belbeis City, Egypt

Full list of author information is available at the end of the article
}

C C The Author(s). 2020 Open Access This article is licensed under a Creative Commons Attribution 4.0 International License, which permits use, sharing, adaptation, distribution and reproduction in any medium or format, as long as you give appropriate credit to the original author(s) and the source, provide a link to the Creative Commons licence, and indicate if changes were made. The images or other third party material in this article are included in the article's Creative Commons licence, unless indicated otherwise in a credit line to the material. If material is not included in the article's Creative Commons licence and your intended use is not permitted by statutory regulation or exceeds the permitted use, you will need to obtain permission directly from the copyright holder. To view a copy of this licence, visit http://creativecommons.org/licenses/by/4.0/. The Creative Commons Public Domain Dedication waiver (http://creativecommons.org/publicdomain/zero/1.0/) applies to the data made available in this article, unless otherwise stated in a credit line to the data. 


\section{Background}

Sacrococcygeal Pilonidal disease is an infection of the skin and subcutaneous tissue at the upper part of the natal cleft of the buttocks [1]. Pilonidal sinus disease (PSD) has an incidence of approximately 26 per 100,000 population with a male predominance of $2: 1$ and the mean age of those affected is from 19 to 30 years of age [2]. Individuals' complaints are varied from asymptomatic midline pits in the natal cleft to symptomatic PSD with chronic discharge, pain and impact upon quality of life and social function [3]. The goals of treatment of PSD include eradication of the sinus tract, complete healing of the overlying skin, and prevention of recurrence. Many different techniques are available for surgical management of PSD [4]. Excision and healing by granulation is still preferred for low recurrence rate (3.4\%) compared with other methods $(20.6 \%)$ for midline closure and (10.3\%) for flap closure, but healing time is lengthy and requires frequent daily dressing with a risk of infection and delayed wound healing [5]. Platelet Rich Plasma (PRP) which contains concentrated growth factors have been reported to accelerate wound healing by $30-40 \%$ giving a satisfactory outcome in the treatment of chronic skin and soft tissue lesions by supplying large amounts of growth factors and chemokines [6]. When platelets become activated, they secrete Seven fundamental protein growth factors initiating all wound healing process, including platelet-derived growth factor (PDGF), epidermal growth factor (EGF), transforming growth factor (TGF), vascular endothelial growth factor (VEGF), Fibroblast growth factor (FGF), connective tissue growth factor (CTGF) \& insulin-like growth factor 1 (ILGF 1), which participate in the acceleration of wound-healing process [7-11]. Altogether, this study aims to evaluate the potential of PRP therapy for accelerating the healing of pilonidal sinus wounds.

\section{Methods}

This is an open-label randomized clinical trial run for 1 year between December 2018 to December 2019.

\section{Ethics committee approval}

A written informed consent was obtained from all patients. The research was conducted with approval from the institutional review board at Kafr El Shiekh University Hospital.

\section{Sampling}

One hundred patients were included, admitted to the General Surgery Department at Kafr El Shiekh University Hospital, Kafr El Shiekh, Egypt. This was an accessible sample of patients presenting to our department. They were divided randomly by closed envelope technique with those having the odd number allotted to group $\mathrm{A}$ and the even number allotted to group $\mathrm{B}$. (Fig. 1).

Group A (control): included 50 patients that underwent a total excision of the pilonidal sinus adopting the lay-open technique and the wound was laid open for secondary healing.

Group B (PRP treated): included 50 patients that underwent the same procedure and on postoperative days 4 and 12 the platelet-rich plasma was injected into the surgical wound. Pits positions varied between each patients with the majority of pits lying in the midline and some patients had secondary pits outside the midline. No patients with pits below the coccyx were involved in the study as the wound volume would be more than $35 \mathrm{cc} .3$ patients had recurrent sinus were included in the study.

\section{Inclusion criteria}

All patients with PSD -including recurrent cases- who underwent Lay Open excision technique for PSD at Kafr El Shiekh University Hospital.

\section{Exclusion criteria}

Patients with pilonidal abscess, diabetics, anemics, patients with Platelet count $<105 / \mathrm{ul}$, patients on anticoagulant treatment, or had wound cavity $>35 \mathrm{cc}$ were disqualified from this trial.

\section{Operative technique}

The operation was done under spinal anesthesia in a prone position. A single dose of 3rd generation cephalosporin (1 g.) was given intravenously $30 \mathrm{~min}$ before surgery. The skin was disinfected with $10 \%$ povidoneiodine. The anal region was excluded from the operative field by drapes. Methylene blue dye was injected through the openings. An elliptical incision was made containing the sinus orifice and extended in-depth to the deep fascia. The diseased area was excised en-block. After hemostasis, the wound was filled with normal saline solution and then drained and the drained amount is measured to find the wound volume, the wound cavity $>35$ cc was excluded from the study to ensure near-equal circumstances for comparison. The wound is then packed with the classic dressing of absorbent sterile cotton gauze.

\section{PRP preparation}

PRP was prepared by the double Spain strategy. The patient was first sent to the university clinical pathology department where $25 \mathrm{cc}$ of venous blood was acquired from the patient by venipuncture of the middle cubital lower arm vein. The blood was collected in seven $4 \mathrm{ml}$ clean vacutainer tubes containing an anticoagulant Sodium Citrate $3.8 \%$. The citrated blood was centrifuged at 

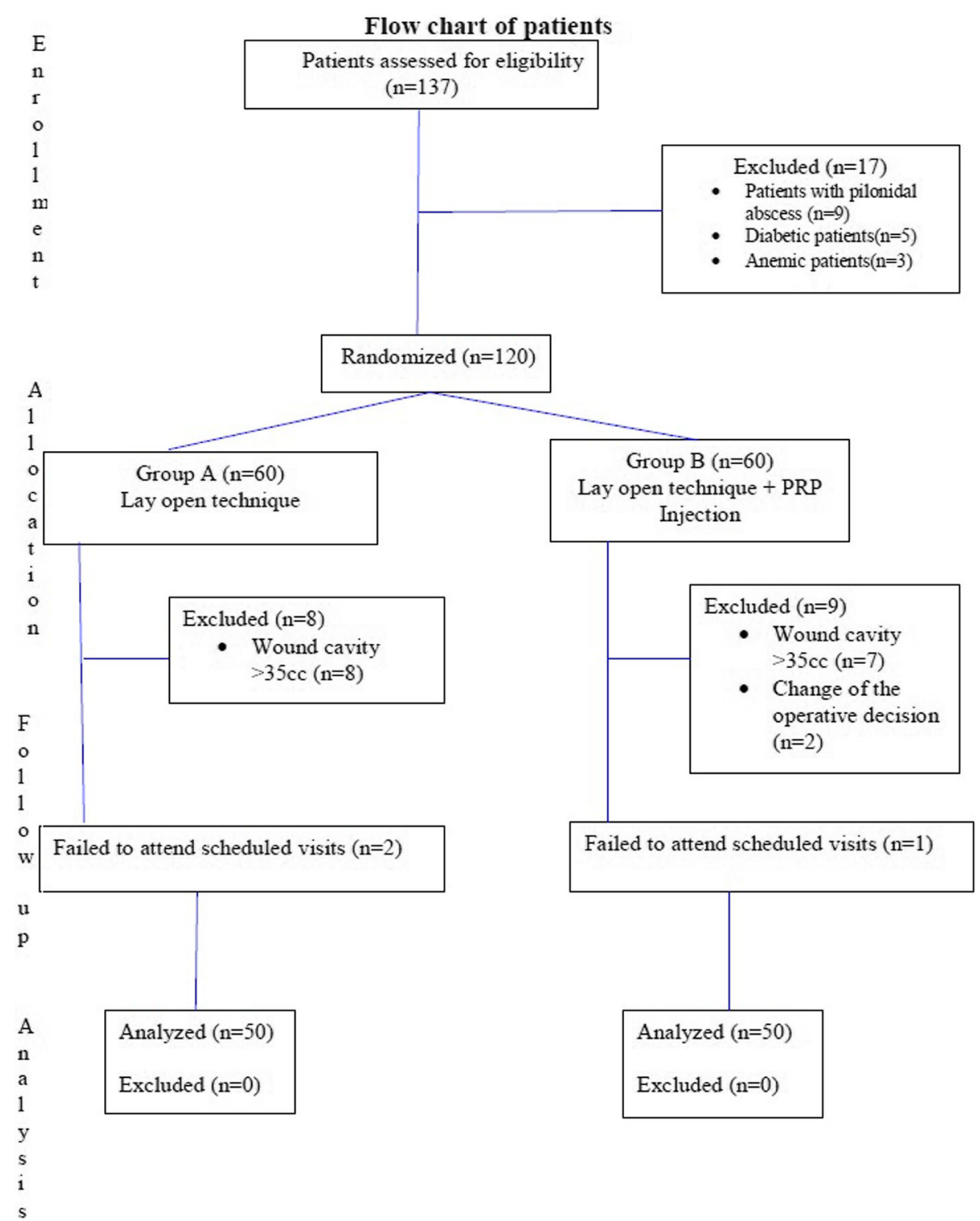

Fig. 1 Flow chart of patients

$1700 \mathrm{rpm}$ for $15 \mathrm{~min}$ at room temperature, separating red blood cells at the bottom with plasma at the top and a "buffy coat" in between. The plasma and the buffy coat were aspirated from every test tube into a syringe and exchanged to another tube then centrifuged again at $3000 \mathrm{rpm}$ for $10 \mathrm{~min}$ at room temperature. After the second centrifugation a two-section plasma was acquired: the upper part, comprising of platelet-poor plasma (PPP); and the lower part, comprising of platelet-rich plasma (PRP). The PPP was delicately aspirated, to separate it from the PRP.

\section{PRP injection method}

Postoperative wound evaluation was done at the outpatient clinic and on the predetermined postoperative days, 4 and 12 PRP was injected in the wound through the granulation tissue beneath the skin to a $13 \mathrm{~mm}$ depth of the wound using an insulin needle $(0.1 \mathrm{cc} / \mathrm{cm} 2)$ at each injection as fast as possible (the whole duration was less than $30 \mathrm{~s}$ ), after that the wound was filled with the remaining PRP. Then, the surface was covered using sterile non-allergenic latex to avoid any PRP leakage for $24 \mathrm{~h}$. After $24 \mathrm{~h}$, the latex cover was removed and the usual dressing was performed.

\section{Postoperative care}

All patients of both groups were discharged on the day of operation. Instructions for home dressing were given for each patient (wound irrigation with normal saline twice a day and classic dressing with absorbent sterile 
Table 1 Demographic findings among the studied group (mean and median are mentioned to summarize data)

\begin{tabular}{|c|c|c|c|}
\hline Variable & Group $A(N=15)$ & Group B $(n=15)$ & $P$-value \\
\hline \multicolumn{4}{|c|}{ Sex (Frequency) } \\
\hline Male & $43(86.6 \%)$ & $40(80 \%)$ & \\
\hline Female & $7(13.4 \%)$ & $10(20 \%)$ & \\
\hline \multicolumn{4}{|l|}{ Age (years) } \\
\hline Mean \pm SD & $26.27 \pm 4.62$ & $25.07 \pm 4.83$ & $1.3(0.2)$ (NS) \\
\hline Median & 26 & 25 & \\
\hline Range & $(18-35)$ & $(18-35)$ & \\
\hline
\end{tabular}

cotton gauze after disinfection with $10 \%$ povidoneiodine).

Ceftriaxone IM/24h for 3 days was prescribed as a post-operative prophylaxis and paracetamol $500 \mathrm{mg}$ tab triple-daily as pain killer with the avoidance of NSAID in order not to interfere with platelet function.

\section{Follow up}

All patients were followed up regularly at the outpatient clinic in scheduled visits on days 4, 6, 9, 12, 17, 22, 27 postoperative and then every week (days 35, 42, 50 postoperative) till complete healing was achieved and Group $B$ patients received the predetermined PRP injections in the wound on postoperative days 4 (first postoperative outpatient clinic visit and to ensure complete hemostasis of the wound) and day 12 (1 week later after the first PRP injection). During each visit, the assessment of the wound capacity and measurement of the pain score $(\mathrm{Nu}-$ meric rating scale from 1 to 10 was used to assess the severity of pain) was performed. Patients were assessed by the same surgeons in every visit.

\section{Parameters of evaluation}

Patients were evaluated regarding post-operative healing; wound volume (primary outcome measure) (Cut off point was set to a certain volume of the wound upon which wound healing was assessed accordingly i.e. total time of healing is dependent on a specific volume capacity of the remaining gap after excision of the sinus and after this certain time, the healing would be called delayed wound healing) and post-operative pain duration (secondary outcome measure) on days 4, 12, 30 and 50 postoperative. Other measured data included the

Table 2 clinical presentation before surgery

\begin{tabular}{llll}
\hline Symptoms & $\begin{array}{l}\text { Group A } \\
(N=50)\end{array}$ & $\begin{array}{l}\text { Group B } \\
(N=50)\end{array}$ & $\begin{array}{l}\text { Chi square test } \\
p \text {-value }\end{array}$ \\
\hline Pain & $17(34.0 \%)$ & $17(34.0 \%)$ & $3.6(0.16)$ NS \\
Discharging sinus & $27(54.0 \%)$ & $20(40.0 \%)$ & \\
Pain and discharge & $6(12.0 \%)$ & $13(26.0 \%)$ & \\
\hline
\end{tabular}

Table 3 symptoms duration before surgery

\begin{tabular}{llll}
\hline Duration of symptoms (months) & Group A & Group B & $P$-value \\
\hline (mean \pm SD) & $9.33 \pm 3.61$ & $9 \pm 3.94$ & 0.8 (NS) \\
Range & $5-17$ & $5-18$ & \\
\hline
\end{tabular}

incidence of wound infection (surgical site infection), the duration of pain killer treatment and time to return to work. The wound volume was assessed by the same method used intra-operatively.

Data were analyzed using the SPSS software package version 20.0 (Prentice-Hall, Chicago, IL, USA). Qualitative data were described using the number and percent. Quantitative data were compared using the student ttest. A comparison between the two groups regarding categorical variables was done using the Chi-square (X2) test. When more than $20 \%$ of the cells have expected count less than 5, correction for Chi-square was conducted using Fisher Exact test or Monte Carlo correlation (MC). A "p" value of $<0.05$ was considered to be statistically significant.

\section{Results}

\section{Demographic data}

Both groups were compared regarding the demographic data (Table 1). Clinical presentation and duration of symptoms are presented in Table 2 and Table 3. The number of pits was comparable in both groups ranging from 3 to 5 pits.

\section{Postoperative follow-up}

In the postoperative period, there was a significant difference between group A and B regarding the time of sitting with a mean of (18.33 and 12.73) days, toilet sitting with a mean of (19.73 and 13.27) days, pain duration with a mean of (16.67 and 10.40) days and return to work with a mean of (24.93-16.27) days respectively as may be seen in (Table 4) (Fig. 2).

The rate of wound healing was estimated by wound volume $(\mathrm{cm})$ starting from day 0 . There was no significant difference in healing rate between both groups noted at days 5 and 10 . But the start point of accelerated healing in the PRP group (B) was detected in day 10, with a highly significant difference detected in day 15 ,

Table 4 Postoperative outcome in both groups regarding

\begin{tabular}{llll}
\hline Variable & $\begin{array}{l}\text { Group A } \\
(\boldsymbol{N}=\mathbf{5 0})\end{array}$ & $\begin{array}{l}\text { Group B } \\
(\boldsymbol{N}=\mathbf{5 0})\end{array}$ & $\begin{array}{l}\text { T test } \\
\mathbf{p} \text {-value }\end{array}$ \\
\hline $\begin{array}{l}\text { Time of comfort } \\
\text { sitting (days) }\end{array}$ & $18.33 \pm 2.41$ & $12.73 \pm 1.75$ & $<0.001^{* *}(\mathbf{H S})$ \\
Toilet sitting (days) & $19.73 \pm 2.60$ & $13.27 \pm 7.15$ & $<0.001^{* *}(\mathbf{H S})$ \\
Pain duration (days) & $16.67 \pm 1.83$ & $10.40 \pm 2.13$ & $<0.001^{* *}(\mathbf{H S})$ \\
Return to work (days) & $24.93 \pm 1.58$ & $16.27 \pm 2.25$ & $<0.001^{* *}(\mathbf{H S})$ \\
\hline
\end{tabular}




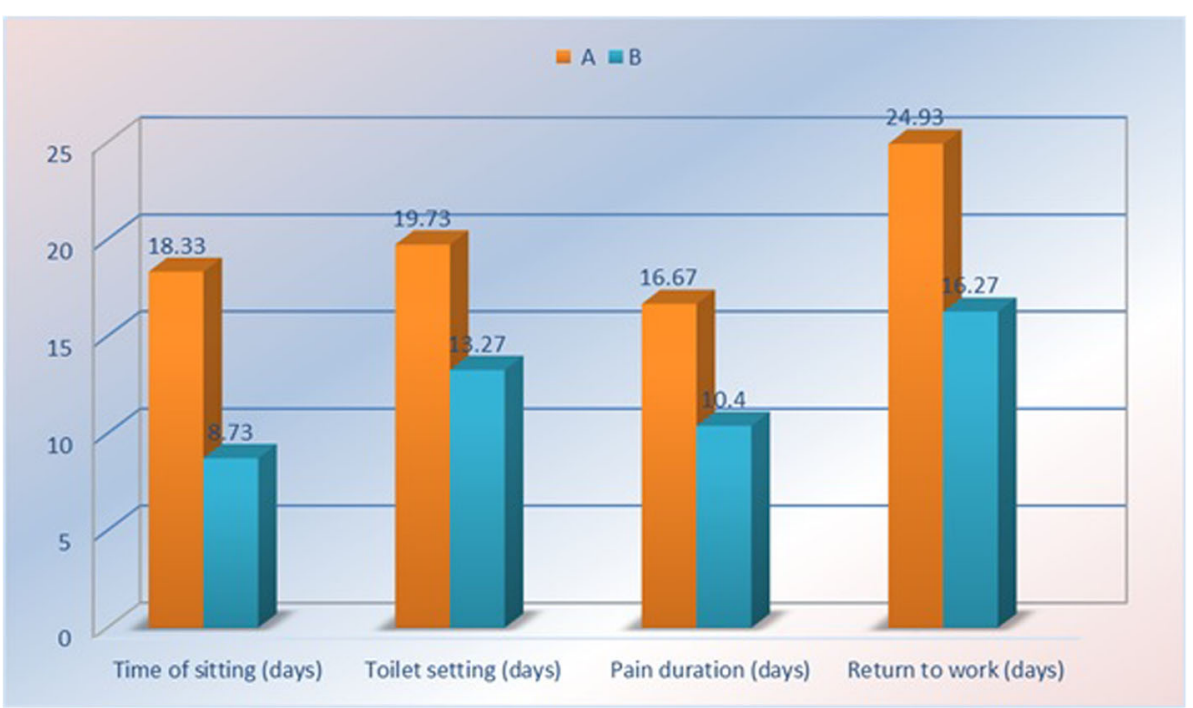

Fig. 2 Postoperative outcome in both groups

20, 25 and 30, with a stationary course after day 30 till day 45 , and showing no significant difference in wound volume between both groups in day 45 (Table 5). The mean time of complete healing was $45 \pm 2.6$ days in group $\mathrm{B}$, while it was $57 \pm 2.4$ days in group A with a $p$ value of 0.001 , with a statistically significant difference which indicates considerable effect in the treated group. (Fig. 3).

\section{Postoperative complications}

Wound infection and delayed wound healing which was found in 3 patients of group A (6\%) (Complete healing was reached at the 75th postoperative day) and only one patient of group B (2\%) (Complete healing was reached at the 60th postoperative day) with a significant difference (Table 6).

\section{CONSORT guidelines}

The study was completely adherent to the CONSORT guidelines as published in 2010 .

Table 5 postoperative follow up regarding wound volume (cm) in comparing with time (days)

\begin{tabular}{llll}
\hline Wound volume (cm) & $\begin{array}{l}\text { Group A } \\
(\boldsymbol{N}=\mathbf{5 0})\end{array}$ & $\begin{array}{l}\text { Group B } \\
(\boldsymbol{N}=\mathbf{5 0})\end{array}$ & $\boldsymbol{P}$-value \\
\hline Day 0 & $30.99 \pm 2.37$ & $30.41 \pm 3.11$ & 0.3 (NS) \\
Day 5 & $29.26 \pm 1.76$ & $29.17 \pm 2.46$ & 0.8 (NS) \\
Day 10 & $26.46 \pm 0.97$ & $22.75 \pm 1.02$ & $<0.001^{* *}(\mathbf{H S )}$ \\
Day 15 & $21.0 \pm 1.0$ & $16.49 \pm 1.55$ & $<0.001^{* *}(\mathbf{H S})$ \\
Day 20 & $17.50 \pm 1.25$ & $10.93 \pm 1.26$ & $<0.001^{* *}(\mathbf{H S})$ \\
Day 25 & $13.68 \pm 0.88$ & $7.46 \pm 0.65$ & $<0.001^{* *}(\mathbf{H S )}$ \\
Day 30 & $10.20 \pm 0.30$ & $4.49 \pm 0.46$ & $<0.001^{* *}(\mathbf{H S})$ \\
Day 45 & $5.09 \pm 0.38$ & $3.15 \pm 0.49$ & $<0.001^{* *}(\mathbf{H S})$ \\
\hline
\end{tabular}

\section{Discussion}

Platelet-rich plasma is a very rich platelet-derived autologous product. Platelet related products have been used in wound healing since 1985 with a satisfactory outcome so far in the treatment of chronic skin and soft tissue lesions, maxillofacial and plastic surgery wounds by providing large amounts of growth factors and chemokines. These growth factors act as a part of the cellular communication network that influences cell division, matrix synthesis and tissue differentiation [12].

This study was conducted to evaluate the potential of PRP in accelerating wound healing of those one hundred patients with sacrococcygeal pilonidal sinus who underwent lay-open excision of pilonidal sinus disease with secondary healing method which is an integral part of enhanced recovery program aiming at reducing morbidity and improving cosmesis.

Many different surgical techniques are recognized for the management of PSD. After excision, the wound may be left open to heal with granulation tissue or may be immediately closed by midline closure or by using a flap (Z-plasty, karydakis, or Rhomboid flap). Excision and healing by granulation is still preferred due to the low recurrence rate of $(3.4 \%)$ compared with other methods (20.6\%) for midline closure and (10.3\%) for using flaps closure. 4 As the operative time is about $25 \mathrm{~min}$ and the surgery is a day-case surgery, that makes the procedure less costly than the other techniques (where extra time and skill are needed for flaps placement as well as the need for drains, multi-drug usage, and more hospital stay).

The rate of wound healing and the time needed to reach the complete wound healing after operation remains the cornerstone of this study, the volume of the 


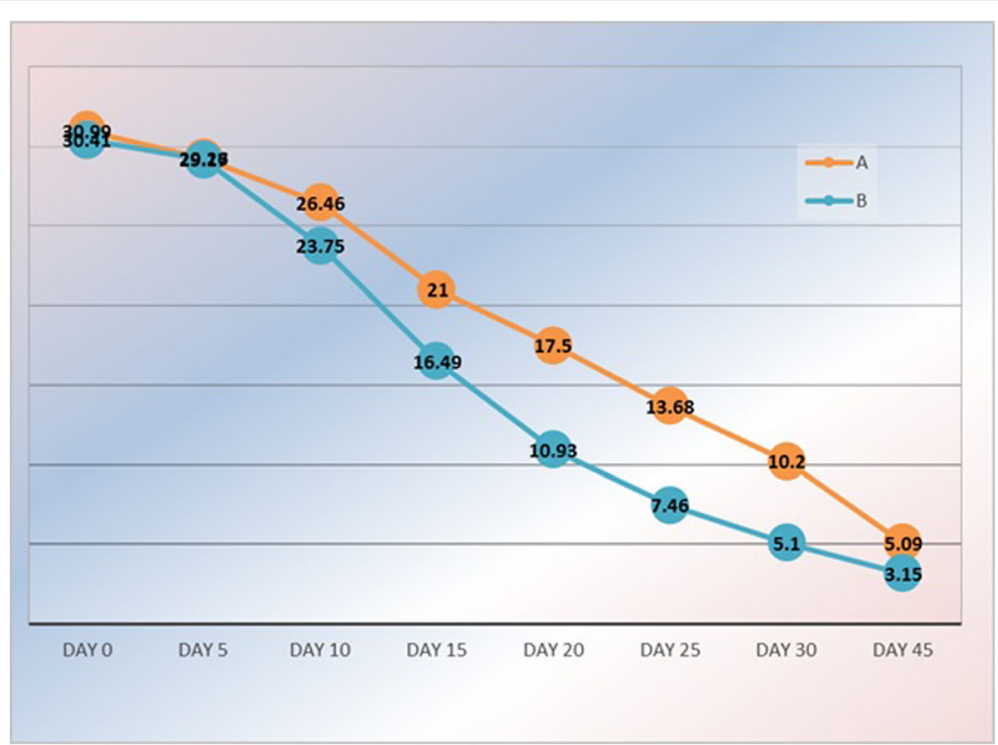

Fig. 3 Mean wound volume in each group for the follow-up period

wound at day 0 (operation day) is nearly equal in both groups $(30.99 \pm 2.37)$ and $(30.41 \pm 3.11)$ in group A and $\mathrm{B}$ respectively with no significant difference ( $p$-value $0.5)$. This starting point assures a fair comparison condition regarding the wound volume.

In group $B$ the acceleration of wound healing was noted on day 10 with no significant difference $(p$-value $=0.06$ ) but was more obvious and remarkable on day 15 and 20 ( $p$-value $=0.001)$ this finding was reflected on the duration of pain $(10.4 \pm 2.31)$ days and the time of comfort sitting $(12.73 \pm 175)$ and the early return to work and normal daily activity $(16.2 \pm 2.27)$. Though the timing of the PRP injections were the same in all cases. Those findings are coming in accordance with the study of Spyridakis and colleagues (2009) [13] on 52 patients who underwent an open excision, divided into two groups 22 and 30 for the control and treatment group respectively.

The starting point of wound volume was similar to our study and accelerated wound healing was also noted in days 10 and 15 .

Regarding postoperative complications, surgical site infection and delayed wound healing was noted in 3 patients in group A (6\%) and one patient in group B (2\%),

Table 6 postoperative complications. ${ }^{*}$ Cut off point was set to a certain volume of the wound upon which wound healing was assessed accordingly

\begin{tabular}{llll}
\hline complication & $\begin{array}{l}\text { Group A } \\
(\boldsymbol{n}=\mathbf{5 0})\end{array}$ & $\begin{array}{l}\text { Group B } \\
(\boldsymbol{n}=\mathbf{5 0 )}\end{array}$ & $\begin{array}{l}\text { Chi square } \\
(\boldsymbol{P} \text {-value) }\end{array}$ \\
\hline Wound infection & $10(20 \%)$ & $3(6 \%)$ & $4.3(0.01)^{*} \mathrm{~S}$ \\
Delayed wound healing* & $3(6 \%)$ & $1(2 \%)$ & $0.3^{* *} \mathrm{NS}$ \\
\hline
\end{tabular}

* Significant

** Not Significant while Baher and colleagues (2013) observed increase in the infection rate in treated group 4 patients (11\%) in comparison with control group one patient (2.7\%). They explained this finding by the possibility that PRP (mainly originate from blood and plasma) provides a favorable condition for bacterial growth [14]. Whereas, Spyridakis and colleagues (2009) [13] noticed the decrease in postoperative infected patients compared with the control group which was explained by the fact that platelets contain antimicrobial proteins that have bactericidal and fungicidal properties. In the case of infection ciprofloxacin and clindamycin were prescribed until control of infection also wound debridement was done whenever necessary to remove the necrotic tissues.

Our study limitation was the strict 1 year period during which only 100 patients were included in the study, more number of participants would have been more beneficial.

\section{Conclusion}

PRP injection is an effective new technique in accelerating the healing of pilonidal wound after surgery, with a significant decrease in post-operative pain, complications and an early return to work compared to minimally invasive surgeries, flaps or endoscopic treatment.

\section{Supplementary information}

Supplementary information accompanies this paper at https://doi.org/10. 1186/s12893-020-00865-x.

\section{Additional file 1.}

\section{Abbreviations}

PSD: Pilonidal sinus disease; CONSORT: Consolidated Standards of Reporting Trials 


\section{Acknowledgements}

Not applicable.

\section{Registration}

ClinicalTrials.gov identifier: NCT04430413, link: https://clinicaltrials.gov/show/ NCT04430413

\section{Authors' contributions}

KAl and MMG designed the study; TAI, NAN and MMG performed the study; RFA and TAl analyzed the data; MMG and RFA wrote and revised the manuscript. All authors read and approved the final manuscript.

\section{Funding}

The authors have no funding or financial relationships to disclose.

\section{Availability of data and materials}

The datasets used and/or analysed during the current study are available from the corresponding author on reasonable request.

\section{Ethics approval and consent to participate}

All procedures performed in studies involving human participants were in accordance with the ethical standards of the institutional research committee and with the 1964 Helsinki declaration and its later amendments or comparable ethical standards. The research was conducted after complete approval from the institution review board at Kafr El Shiekh University Hospital. Also, a written informed consent from the patients or their relatives for ethical consideration.

\section{Consent for publication}

A written informed consent from the patients or their relatives for ethical consideration.

\section{Competing interests}

The authors declare that they have no competing interests.

\section{Author details}

'General Surgery Department, Kafr El Shiekh University Hospital, Kafr El Shiekh, Egypt. ${ }^{2}$ Belbeis City, Egypt. ${ }^{3}$ Clinical Pathology Department, Kafr El Shiekh University Hospital, Kafr El Shiekh, Egypt.

Received: 26 March 2020 Accepted: 7 September 2020

Published online: 22 September 2020

\section{References}

1. Khanna A, Rombeau J. Pilonidal disease. Clinical Colon Rectal Surgery. 2011; 19(24):46.

2. Notaro JR. Management of recurrent pilonidal disease. Seminars in Colon and Rectal Surgery. 2003;14(4):173-85.

3. Hull TL, Wu J. Pilonidal disease. Surg Clin N Am. 2002;82(6):1169-85.

4. Darwish A, Eskandaros M, Hegab A. Sacrococcygeal pilonidal sinus: modified sinotomy versus lay-open, limited excision, and primary closure. Egyptian J Surg. 2017;36(1):13-9.

5. McCallum I, King PM, Bruce J, Al-Khamis A. Healing by primary versus secondary intention after surgical treatment for pilonidal sinus. Cochrane Database Syst Rev. 2007;4.

6. Ferrara N, Henzel WJ. Pituitary follicular cells secrete a novel heparin-binding growth factor specific for vascular endothelial cells. Biochem Biophys Res Commun. 1989:161(2):851-8.

7. Veevers-Lowe J, Ball SG, Shuttle worth A, Kielty CM. Mesenchymal stem cell migration is regulated by fibronectin through a5 31 -integrin-mediated activation of PDGFR- $\beta$ and potentiation of growth factor signals. J Cell Sci. 2011;124(8):1288.

8. Corman M, Brian B. Erin M. pilonidal sinus. Colon, rectal and anus. surgery. 2005;5(19):616-25.

9. Oncel M, Kurt N, Kement M, Colak E, Eser M, Uzun H. Excision and marsupialization versus sinus excision for the treatment of limited chronic pilonidal disease: a prospective, randomized trial. Techniques in Coloproctology. 2002;6(3):165-9.

10. Al-Jaberi TMR. Excision and simple primary closure of chronic pilonidal sinus. Eur J Surg. 2001;167(2):133-5.
11. Elgohary $H$, Oraby E. Pilonidal sinus: minimal excision and primary closure under local anesthesia. The Egyptian Journal of Surgery. 2015;34(4):287-92.

12. Redler LH, Thompson SA, Hsu SH, Ahmad CS, Levine WN. Platelet-rich plasma therapy: A systematic literature review and evidence for clinical use. The Physician and Sports medicine. 2011;39(1):42-51.

13. Spyridakis M, Christodoulidis G, Chatzitheofilou C, Symeonidis D, Tepetes K. The role of the platelet-rich plasma in accelerating the wound-healing process and recovery in patients being operated for pilonidal sinus disease: preliminary results. World J Surg. 2009;33(8):1764-9.

14. Bahar M, A kbarian M, Azadmand A. Investigating the effect of autologous platelet-rich plasma on pain in patients with pilonidal abscess treated with surgical removal of extensive tissue. Iran Red Crescent Med J. 2013;15(11): $10-3$.

\section{Publisher's Note}

Springer Nature remains neutral with regard to jurisdictional claims in published maps and institutional affiliations.
Ready to submit your research? Choose BMC and benefit from:

- fast, convenient online submission

- thorough peer review by experienced researchers in your field

- rapid publication on acceptance

- support for research data, including large and complex data types

- gold Open Access which fosters wider collaboration and increased citations

- maximum visibility for your research: over $100 \mathrm{M}$ website views per year

At BMC, research is always in progress.

Learn more biomedcentral.com/submissions 